\title{
CONSTITUCIÓN Y GÉNESIS DE LA SUBJETIVIDAD. APORÉTICA DE LA NOCIÓN DE SUJETO EN M. FOUCAULT Y SOLUCIONES DESDE G. DELEUZE
}

\author{
LUIS SÁEZ RUEDA \\ Universidad de Granada
}

\begin{abstract}
RESUMEN: El trabajo intenta mostrar la estructura aporética de la concepción que el último Foucault posee respecto al sujeto. El autor defiende dos tesis fundamentales. Según la primera, existe una aporía insostenible entre la constitución del sujeto desde el saber y el poder, por un lado, y la auto-experiencia creativa de la subjetividad, por otro, a pesar de los argumentos foucaultianos que se esfuerzan por hacerlas compatibles. Tal auto-experiencia creativa es analizada, sobre todo, como supuesta en la ontología de nosotros mismos, porque es en ella donde se manifiesta la aporía indicada de un modo más amplio. Desde este ámbito, el autor estudia también dicha aporía en la formulación foucaultiana de las prácticas de sí, que concretan la auto-experiencia supuesta en la ontología de la actualidad. Según la segunda tesis, la aporía insostenible e inherente al pensamiento de Foucault en esos dos ámbitos exige, para su solución, la diferenciación entre constitución del sujeto (desde el campo sociopolítico) y génesis de la subjetividad (desde la naturaleza considerada como physis). Para aclarar esta diferencia, el ensayo recurre a concreciones diversas del pensamiento de G. Deleuze.
\end{abstract}

PALABRAS CLAVE: constitución; génesis; individuación; physis; subjetividad.

\section{Constitution and genesis of subjectivity Aporhetics of M. Foucault's notion of subject and solutions from G. Deleuze}

ABSTRACT: The essay tries to show the aporetic structure of the conception that the last Foucault has of the subject. The author defends two fundamental theses. According to the first, there is an unsustainable aporia between the constitution of the subject from knowledge and power, on the one hand, and the creative self-experience of subjectivity, on the other, despite Foucault's arguments that try to make them compatible. Such creative self-experience is analyzed, above all, as assumed in the ontology of ourselves, because it is in it where the mentioned aporia manifests itself in a broader way. From this area, the author also studies this aporia in Foucault's formulation of self-practices, which concretize the supposed self-experience in the ontology of ourselves. According to the second thesis, the unsustainable aporia inherent to Foucault's thought in these two areas requires, for its solution, the differentiation between the constitution of the subject (from the socio-political sphere) and the genesis of subjectivity (from nature considered as physis). To clarify this difference, the essay draws on different concretions of the philosophy of G. Deleuze.

KEY WORDS: constitution; genesis; individuation; physis; subjectivity.

\section{INTRODUCCIÓN}

En lo que viene conociéndose como la última etapa del pensamiento foucaultiano - en la que, tras los ejes del «saber» y el "poder», centra su atención en el del «sujeto»- se condensan los problemas cruciales de toda su obra. En esa fase reconstruye los ejes temáticos de su trabajo anterior a través del tercer y último eje, el del sujeto. «No es el poder, sino el sujeto, el tema general 
de mi investigación», afirma ${ }^{1}$. El problema central que Foucault abre con ello es el que concierne a las condiciones supuestas en el fenómeno de la relación auto-experiencial del sujeto. La búsqueda de tales condiciones, como se sabe, conduce, no a estructuras a priori yacentes en el sujeto mismo, sino a procesos contingentes e históricos que niegan su supuesta naturaleza e identidad sustancial. El sujeto alcanza una relación auto-experiencial en la medida en que se constituye a sí mismo a través de prácticas que van unidas a la noción de cuidado de sí, inquietud de sí, gobierno de sí y semejantes. Ahora bien, si tal problema, así circunscrito, posee para la filosofía del presente una enorme significatividad, como se atestigua en la multitud de estudios a los que ha dado lugar, si señala «una mutación de la filosofía» cuya trascendencia nos induce a lamentar que la obra foucaultiana haya "quedado brutalmente interrumpida ${ }^{2}$, se debe, ante todo, a la circunstancia de que nos fuerza a pensar la paradoja al menos prima facie - de una autoconstitución de sí, de una cierta interioridad, que convive con el fenómeno de la constitución del sujeto desde el saber y el poder. Lo que alimenta la interrogación a propósito del último Foucault es, así, un problema estructural que está incrustado en la totalidad de su investigación y, expresado más esencialmente, en la dinámica tensional de su pensar: la relación entre ser-constituido y auto-constitución en el sujeto o, en un lenguaje más preciso, entre la subjetivación y la subjetividad ${ }^{3}$. Pero esta tensión entre sujeto constituido y sujeto constituyente de sí se complica al comprobar cómo, también en su última época, Foucault se expresa de modo ambiguo y, diríamos, paradójico, de tal modo que la auto-constitución del sujeto aparece, ella misma, como efecto de una constitución a través de procesos que lo conducen a convertirse en objeto para sí mismo ${ }^{4}$. Desde una segunda perspectiva, en cambio, el sujeto se nos presenta como autocreativo. Interesado en afirmar su libertad, en efecto, describe Foucault el cuidado de sí como una «práctica de

1 Foucault, M., «El sujeto y el poder», post-scriptum a Dreyfus, H. L. / Rabinow, P., Michel Foucault. Más allá del estructuralismo y la hermenéutica, Nueva Visión, Buenos Aires 2001 (orig.: 1982), pp. 241-259, p. 242.

2 En este tono enfático se expresa Deleuze tras la muerte de Foucault en 1984. Deleuze, G., «sobre los principales conceptos de Michel Foucault», en: Deleuze, G., Dos regímenes de locos. Textos y entrevistas (1975, 1995), Pre-Textos, Valencia 2007 (orig.: 2003), pp. 223-236, p. 236.

3 Con el término subjetividad se refiere Foucault a «la manera en que el sujeto hace la experiencia de sí mismo en un juego de verdad en el que tiene relación consigo». V. «Foucault» (orig.:1984), en: Foucault, M., Estética, ética y hermenéutica. Obras esenciales III, Paidós, Barcelona 1999 , pp. $363-368$, p. 365.

4 Foucault es claro al respecto en 1984. Distingue tres modos de subjetivación: a través del saber, de las formas de gobierno y ese modo de subjetivación que consiste en «la formación de los procedimientos mediante los cuales el sujeto es conducido a observarse a sí mismo, a analizarse, a descifrarse (...). Se trata, en suma, de la historia de la "subjetividad" (...)» (Ibíd., p. 365. Cfr. pp. 365-367). 
autotransformación del sujeto», «un ejercicio de uno sobre sí mismo, mediante el cual intenta elaborarse, transformarse y acceder a cierto modo de ser $»^{5}$.

Pues bien, esta actividad auto-constituyente no es exclusiva de las prácticas de sí, sino que es condición, también, del entero esfuerzo del sujeto por reconstruir los dinamismos históricos que lo han conformado. Concierne esto último a la caracterización de su entera filosofía como ontología de la actualidad u ontología histórica de nosotros mismos. Dado que esta esfera de auto-experiencia es más general que la de las prácticas de sí, dedicaremos más atención a la aporética que aparece en ella, para pasar finalmente a una revisión de su concreción en el cuidado de sí. Ahora bien, quisiéramos mostrar que es la entera filosofía foucaultiana la que está involucrada en esta cuestión. Comenzaremos analizando qué estructura posee la constitución del sujeto desde los dispositivos saber-poder, en la que detectamos una doble dimensionalidad, la del plano horizontal de las facticidades y la del plano vertical del acontecimiento. Este entretejimiento es esencial a la hora de interpretar el sentido de una auto-constitución en la subjetividad, que arraiga, igualmente, en el orden acontecimental. La aporética que iremos descifrando progresivamente en el pensamiento foucaultiano irá demandando soluciones, que remitimos a la filosofía de Deleuze.

\section{El SUJETO COMO CONSTITUIDO POR ACONTECIMIENTOS, UNA PARADOJA}

El sentido de un sujeto que, tanto en las prácticas de sí como en la ontología de nosotros mismos, hace experiencia de sí mismo, conduce necesariamente a indagar qué instancia es la realmente constituyente. La primera paradoja que encontramos en el pensamiento foucaultiano consiste en que este orden constituyente es acontecimental y el acontecimiento, como se verá más tarde, es ya acontecimiento-pensamiento (y no sólo coacción desde el poder). Aunque la constitución del sujeto corre a cargo de los dispositivos saber-poder, separamos en el subsiguiente análisis los ejes del saber y del poder por razones puramente analíticas, para reunirlos posteriormente.

\subsection{Constitución desde el saber como acontecimiento: el archivo y las positividades}

El primer eje constituyente que abordó Foucault es el del saber. Su análisis está ligado al nombre de arqueología y se extiende, aproximadamente, de 1961 a 1969, desde Las palabras y las cosas a La arqueología del saber. La potencia constituyente recae sobre los discursos (o juegos) de verdad. Ellos conforman, no meramente aquello que se predica como verdadero respecto a las cosas,

5 Foucault, M., «Ética del cuidado de sí como práctica de la libertad», en: Foucault, M., Estética, ética y hermenéutica, pp. 393-415, p. 394. 
sino, a su través, a éstas en tanto tal, convirtiéndolas en «objeto» del saber. La fenomenológica «auto-presentación» de las cosas mismas es sustituida, así, en el pensamiento foucaultiano, por la presentación que de ellas se hace en el discurso. «En una palabra, se quiere, totalmente, prescindir de las "cosas". "Despresentificarlas" (...). Sustituir el tesoro enigmático de "las cosas" previas al discurso por la formación regular de los objetos que sólo en él se dibujan ${ }^{6}$. Y, puesto que, como subraya nuestro filósofo mucho más tarde, la arqueología del saber se ocupa de aquellos juegos de verdad en los que el propio sujeto se plantea como objeto de saber posible, el resultado es un trazado de diversas subjetivaciones, es decir, de modos de constitución del sujeto, como, por ejemplo, los que, a través de una "partición normativa», lo hacen reconocerse como loco o enfermo mental (frente a sus respectivos opuestos) en vinculación con prácticas como la psiquiatría o la medicina clínica (Historia de la locura, Nacimiento de la clínica $)^{7}$ o los que, de un modo amplio, en el medium de las ciencias humanas y bajo la óptica humanista, lo hacen aparecer, en general, como hombre - esa «invención reciente (...), un simple pliegue en nuestro saber ${ }^{8}$. Los discursos de verdad, pues, cualifican al sujeto, en vez de presuponerlo: no hay, bajo ellas, ni un «sujeto fundador», ni una "experiencia originaria» (un sujeto pre-discursivo o pre-lógico que pudiera retomarse ulteriormente en la forma del cogito $)^{9}$.

Que los discursos no sean «expresión» de una subjetividad anterior, de un agente constituyente, sino que lo constituyan, es algo que está vinculado a la circunstancia de que su ser consiste en su propio discurrir, en su devenir mismo. Son acontecimientos. Un objetivo fundamental que se propone Foucault, en efecto, es el de «restituir al discurso su carácter de acontecimiento» ${ }^{10}$. Este carácter de la filosofía foucaultiana, la de una ontología del acontecimiento, se opone tanto a la corriente fenomenológico-hermenéutica como al estructuralismo. Frente a la primera, por un lado, porque el acontecer discursivo no coincide con una continuidad histórica en la que se enlazarían las interpretaciones del sentido o de los actos fundadores de éste, susceptibles de ser investigados mediante una fenomenología histórica ${ }^{11}$, sino que es, más bien, un modo de operar, un devenir especificado en la dimensión pragmática de los enunciados, de la función enunciativa del lenguaje: «el enunciado, a la vez que surge en su materialidad, aparece con un estatuto, entra en unas tramas, se sitúa en campos de utilización, se ofrece a traspasos y a modificaciones posibles, se integra

6 Foucault, M., La arqueología del saber, Siglo XXI, Madrid/México D.F. 1979 (orig.: 1969), p. 78.

7 Cfr. Foucault, M., «Foucault», pp. 364-365. 1966), p. 9

9 Cfr. Foucault, F., El orden del discurso, Tusquets, Buenos Aires 2005 (orig.: 1970), pp. 49-51. En este escrito, que corresponde a la Lección inaugural en el Collège de France pronunciada el 2 de diciembre de 1970, Foucault afirma que está expresando las líneas maestras de su trabajo ulterior (Cfr. p. 51).

10 Ibid., p. 51.

11 Cfr. Foucault, F., La arqueología del saber, pp. 341-342. 
en operaciones y en estrategias ${ }^{12}$. Pero el acontecimiento discursivo, por otra parte, no se somete - contra el estructuralismo, que es siempre un movimiento anti-fenomenológico- a esa otra continuidad propia del orden sistémico de la estructura, totalidad organizadora de significantes y apolíneamente anterior a su praxis ejecutiva. Lo que caracteriza al peculiar orden del acontecer discursivo es romper con cualquier continuidad, pues es el espacio abrupto de una lucha. Si posee un orden, es el que estaría asignado a una teoría de las sistematicidades discontinuas ${ }^{13}$. Y en este carácter de su ordenamiento, que responde a las exigencias de un pensamiento de la diferencia al que Foucault siempre ha permanecido fiel, radica lo esencial que quisiéramos destacar.

La «sistematicidad discontinua» es el espacio, podríamos decir, de un orden diferencial litigioso. La discontinuidad en el orden es una fragmentación, una dispersión que, en ausencia de una identidad central, se organiza en virtud de relaciones diferenciales. Y ello, a nuestro juicio, se especifica en dos planos: el plano horizontal, podríamos decir, de la multiplicidad de diferencias que aparecen en un campo discursivo, por un lado, y el plano vertical, por otro, del dinamismo operante que las hace aparecer en su articulación, que las con-forma y ordena subyacentemente. Para designar al primero suele utilizar Foucault los conceptos de «formación discursiva» o "positividad». Una positividad, sin embargo, no coincide, para nuestro autor, con una suma de facticidades, en el sentido de hechos discursivos o contenidos de facto, pues los discursos, en coherencia con la ontología acontecimental mencionada anteriormente, son un plexo de acontecimientos discursivos relacionados entre sí $^{14}$. Es obvio que la positividad posee una materialidad relacionada con un mundo social ostensible, pues los acontecimientos diferentes que la conforman se forjan en prácticas discursivas signables como "un conjunto de enunciados (...) que son admitidos, institucionalizados, transmitidos y a veces admitidos como ciencias ${ }^{15}$. Ahora bien, esa heterogeneidad material adquiere dinamismo sólo por mor de la vertebración que las liga y les confiere su fuerza formadora o constituyente. En ese sentido, se puede decir que las positividades son regularidades, reglas de formación. "Analizar positividades es — dice Foucault- mostrar de acuerdo con qué reglas una práctica discursiva puede formar grupos de objetos,

12 Ibíd., p. 177. Este operar será más claramente especificado por Foucault más tarde, cuando tematice el nexo entre saber y poder. El operar es potencia o fuerza. Se trata, pues, en Foucault, como hemos defendido en otro lugar, de una ontología de la fuerza que hace derivada de ésta, de la fuerza, al sentido, invirtiendo la ontología del sentido fenomenológicohermenéutica (que hace derivada a la fuerza respecto al sentido). Cfr. Sáez RuedA, L., Ser errático. Una ontología crítica de la sociedad, Trotta, Madrid 2009, caps. 5 y 7.

13 Foucault, M., El orden del discurso, p. 58.

14 Más concisamente, son una multiplicidad de acontecimientos que no responden a un «juego de causas y efectos en la unidad informe de un gran devenir», sino que forman lo que podríamos llamar, sintéticamente, series diferenciales, series conectadas por la diferencia misma entre ellas. Cfr. Ibid., pp. 51-57.

15 Foucault, M., La arqueología del saber, p. 299. 
conjuntos de enunciaciones, juegos de conceptos, series de elecciones teóricas. (...) $\gg^{16}$. Pero tales reglas no son formales; son inherentes a una operatividad que radica en las inter-relaciones, tanto entre ejercicios de discurso como de los eventos que tal discurso cualifica. Es en el plano «vertical» donde las reglas operativas de un tipo de discurso revelan con mayor claridad que su nexo pertenece a una lógica del acontecimiento. En esta dirección se refiere Foucault al archivo. Éste, podría decirse, actúa respecto a la heterogeneidad que conforma una positividad como un tipo de orden que adopta la forma de un universal singular, si le sustraemos a esa «universalidad» todo carácter identitario. Su caracterización responde a la pregunta, en efecto, por la singularidad de cada elemento discursivo. "La descripción de los acontecimientos del discurso plantea otra cuestión muy distinta: ¿cómo es que ha aparecido tal enunciado y ningún otro en su lugar? ${ }^{17}$. Este universal en la multiplicidad de singularidades discursivas es, pues, un apriori de la aparición diferencial de éstas. Su peculiaridad sutil consiste en que no es de carácter trascendental, porque ha surgido en el devenir histórico, pero tampoco es una facticidad meramente empírica. Es un «apriori histórico» operante, orden inmanente a la pluralidad de acontecimientos cuya aparición conforma una positividad. El archivo es

lo que podría llamarse un apriori histórico. Yuxtapuestos esos dos términos hacen un efecto un tanto detonante; entiendo designar con ello un apriori que sería no condición de validez para unos juicios, sino condición de realidad para unos enunciados. No se trata de descubrir lo que podría legitimar una aserción, sino de liberar las condiciones de emergencia de los enunciados, la ley de su coexistencia con otros, la forma específica de su modo de ser, los principios según los cuales subsisten, se transforman y desaparecen ${ }^{18}$.

Podemos ahora precisar la relación entre positividad y archivo. La «verticalidad» del archivo respecto a la «horizontalidad» de la positividad no especifica una anterioridad, ni histórica ni suprahistórica. Por el contrario, es completamente inmanente. Indica - a nuestro juicio- una primacía genética del ordenamiento respecto a lo ordenado. Ahora bien, esa primacía acontecimental y genética, ¿no escaparía, por su propio sentido, a su mera acepción coactiva, ligada a las positividades socio-políticas? En el ámbito del poder ocurre algo similar, como veremos.

\subsection{Constitución desde el poder como profundidad acontecimental: problematizaciones y estrategias}

¿Cómo se relacionan los ejes del saber y del poder respecto a la constitución del sujeto? El problema del poder ha estado presente, como se sabe, en la obra foucaultiana desde el inicio, pero es tematizado de un modo expreso,

16 Ibid., p. 304.

17 Ibid., p. 44. V. toda la «Introducción».

18 Ibíd., pp. 216-217. 
aproximadamente, de 1970 a 1976. En su operatividad constituyente, el saber no articula discursos de verdad de acuerdo con esa "coacción sin coacciones» que ejerce, según Habermas, el mejor argumento ${ }^{19}$. La verdad está atravesada por el poder. «Lo importante, creo, es que la verdad no está fuera del poder, ni sin poder (...), está producida aquí gracias a múltiples imposiciones (...). Cada sociedad tiene su régimen de verdad, su "política general" de la verdad» ${ }^{20}$. Poder y saber, así, se copertenecen, aunque el primero prima sobre el segundo en la constitución. Foucault los vincula, por eso, en el término «dispositivos saberpoder», subrayando que entre ellos "no hay exterioridad» y que, «incluso si poseen su propio papel específico», se articulan «en virtud de su diferencia» ${ }^{21}$. Como sintetiza Deleuze al respecto, «entre el poder y el saber existen diferencias de naturaleza, existe heterogeneidad; pero también existe presuposición recíproca y capturas mutuas; por último, existe primacía de uno sobre otro» ${ }^{22}$. La constitución del sujeto se escora ahora hacia el eje del poder, pero teniendo en cuenta que éste opera siempre mediadamente, promoviendo prácticas discursivas de verdad, es decir, construyendo conceptos y confiriendo perfil a campos de análisis como la psique, la personalidad, la conciencia, etc. Así, por ejemplo, en los últimos siglos — según nos relata Foucault en Vigilar y castigar - el poder del castigo se transforma y expande mediante todo un aparato «epistemológico-jurídico», situando «la tecnología del poder en el principio tanto de la humanización de la penalidad como del conocimiento del hombre» y produciendo, así, el «alma moderna ${ }^{23}$.

El escoramiento del problema de la constitución del sujeto hacia este último invita a analizarlo desde la especificidad que introduce. En este punto reencontramos, a otro nivel, las peculiaridades morfológicas de una ontología del acontecimiento. Si en el ámbito del saber se partía del discurso como una multiplicidad de acontecimientos discursivos cuyo orden diferencial no los disuelve en una continuidad (de sentido o estructural), sino que los hace aparecer en su singularidad, una configuración de poder se le revela a Foucault, análogamente, como un espacio gestado por una «eventualización». Quiere decir ello que no está configurado como una unidad idéntica a sí misma, sino como un acontecimiento singular articulado, él mismo, por una retícula polimorfa de eventos procesuales. "Allí donde se estaría bastante tentado a referirse a una evidencia que se impone de la misma manera para todos, se trata de hacer surgir una "singularidad"» $\mathrm{y}$ "construir en torno al evento singular analizado

19 Habermas, J., "Teorías de la verdad», en: Habermas, Teoría de la acción comunicativa. Complementos y estudios previos, Cátedra, Madrid 1989 (orig.: 1972), pp. 113-188, p. 140. Cfr. pp. 138-150.

20 Foucault, F., «Verdad y Poder», en: Foucault, Microfísica del poder, La Piqueta, Madrid 1991 (orig.: 1971), pp. 175-179, p. 187.

21 Foucault, F., La voluntad de saber, Siglo XXI, Madrid 1998 (orig.: 1976), pp. 118-119.

22 Deleuze, G., Foucault, Paidós, Barcelona 1998 (orig.: 1976), p. 102, V., ampliamente, pp. 99-105.

23 Foucault, M., Vigilar y castigar. Nacimiento de la prisión, Siglo XXI, México 1976 (orig.: 1975), p. 30 . 
como proceso un "polígono" o, más bien, un "poliedro de inteligibilidad" ${ }^{24}$. Pues bien, cualquier fenómeno de poder, tomado como acontecimiento, torsiona la historia, emerge en cuanto «discontinuidad» ${ }^{25}$, lo que quiere decir que se relaciona diferencialmente con otros y que él mismo está fragmentado inmanentemente en un campo diferencial.

De modo análogo a como, en el saber, el problema ontológico clave residía en analizar la sistematicidad discontinua de un campo discursivo, podemos encontrar ahora en los campos del poder este orden en la discontinuidad. Y también, en dos planos. En el plano horizontal, el poder está ya materializado positivamente en una multiplicidad de procesos del ámbito social. Estos procesos cobran efectividad en prácticas, en relaciones humanas que se caracterizan por ser acciones sobre acciones a través de las cuales los actores de la praxis social intentan, recíprocamente, influir en la conducta. Son estrategias ${ }^{26}$. Las estrategias son estos eventos que conforman un campo de poder en su acontecer. En tal sentido, no coinciden con facticidades estancas (instituciones, formaciones políticas o agrupaciones de cualquier tipo); son procesos operativos, «modos de funcionamiento ${ }^{27}$ que atraviesan tales facticidades, materializándose en ellas y desbordándolas. En su confrontación, no se suman; articulan una pluralidad entretejida cuyo ordenamiento consiste en la relación diferencial misma por la que se encuentran y entran en litigio ${ }^{28}$. De ahí que devengan en la forma de un agonismo sin sujeto, ni central ni subyacente como una continuidad que las abarcase. Sí hay, por supuesto, intenciones individuales; las hay múltiples y multiformes; pero, como estrategias nodulares, su devenir, su acontecer, da lugar a grandes estrategias anónimas en las que se plasma una «intencionalidad asubjetiva $»^{29}$.

24 Foucault, F., «Mesa redonda, 1978», en: La imposible prisión: debate con Michel Foucault, Anagrama, Barcelona 1982 (orig.: 1982), pp. 55-82, pp. 60-61. Tal es, por ejemplo, la encarcelación penal tomada como acontecimiento histórico, a cuyas caras se está refiriendo Foucault (Cfr. pp. 67-72). Que sea una multiplicidad de eventos singulares implica que posea también una multiplicidad de efectos. «Entender estos efectos — dice Foucault- bajo su forma de acontecimientos históricos (...) es más o menos mi tema» (Ibíd., p. 71).

25 Ibid., p. 60.

26 «Los mecanismos de puesta en funcionamiento del poder se pueden interpretar en términos de estrategias» (Foucault, F., «El sujeto y el poder», post-scriptum a DreYFus, H. L./ Rabinow, P., Michel Foucault. Más allá del estructuralismo y la hermenéutica, Nueva Visión, Buenos Aires 2001 —orig.: 1982-, pp. 241-259, p. 258). Cfr. todo el parágrafo «Relaciones de poder y relaciones de estrategia», pp. 257-259. «El poder — dice en otro lugar- es el nombre que se da a una compleja situación estratégica en una sociedad» (Foucault, F., Voluntad de saber, p. 115). Para la comprensión del poder como «acciones sobre acciones», cfr. FoucAult, F., «El sujeto y el poder», pp. 252-254.

27 Foucault, M., «Poderes y estrategias» (orig.: 1977), en Microfísica del poder, La Piqueta, Madrid 1991, pp. 163-174, especialmente 164-166.

28 «Cada relación de poder pone en funcionamiento diferenciaciones que son al mismo tiempo sus condiciones y sus efectos» (Foucault, M., «El sujeto y el poder», p. 256).

29 «(...) Las relaciones de poder son a la vez intencionales y no subjetivas. Si, de hecho, son inteligibles, no se debe a que sean el efecto, en términos de causalidad, de una instancia 
En el plano «vertical» — de manera análoga a como ocurría en el eje del saber- los dispositivos del poder han de ser analizados como aquello que, siendo contemporáneo de la correspondiente gran estrategia y transformándose con ella, le confiere un ordenamiento y actúa como su condición de realidad, más allá de lo meramente presente y más acá de un supuesto subsuelo trascendental. Desde ese punto de vista, el poder se revela como relación de fuerzas, siendo la «fuerza» una dimensión intensiva que se caracteriza por su capacidad de afectar. Las fuerzas, en efecto, operan en estrategias, pero, consideradas desde sí mismas, se caracterizan por su capacidad de afectar y ser afectadas ${ }^{30}$. Ahora bien, las fuerzas en relación pueden ser consideradas, además, como una realidad no categoremática; forman campos problemáticos. Dicho de otro modo, son problematizaciones que actúan como «condiciones en las que se pueden dar respuestas posibles», dificultades convertidas en problemas «a los que las diversas soluciones buscarán aportar una respuesta» ${ }^{31}$.

\subsection{El nexo saber-poder: procedencia y emergencia}

Se desprende de los análisis anteriores que la dimensión responsable de la constitución del sujeto, en cuanto campo a-subjetivo de dispositivos saber-poder, reúne en la inmanencia dos caras que son haz y envés una respecto a la otra: por un lado, es una configuración de presencias entrelazadas (las positividades del saber y las estrategias del poder), por otro, consiste - podríamos decir- en la dynamis de su ordenamiento diferencial (el archivo en el saber; las problematizaciones en el poder). Pues bien, si hubiera que remitir la constitución del sujeto a un estrato, por así decir, irrebasable, tendríamos que hacerlo en el lenguaje de la potencia, de la fuerza, de la intensio, pues en los dispositivos saber-poder, como hemos visto, este último posee preeminencia constituyente. A este respecto, la diferencia que realiza Foucault, explicitando su herencia nietzscheana, entre procedencia (Herkunft) y emergencia (Entstehung), nos proporciona, a nuestro juicio, la clave decisiva. La genealogía, que supone — claro está- una arqueología con ella entreverada, concibe la «procedencia» como el conjunto

distinta que las "explicaría", sino a que están atravesadas de parte a parte por un cálculo: no hay poder que se ejerza sin una serie de miras y objetivos. Pero ello no significa que resulte de la opción o decisión de un sujeto individual (...); sucede que no hay nadie para concebirlas [a las estrategias] y muy pocos para formularlas: carácter implícito de las grandes estrategias anónimas, casi mudas, que coordinan tácticas locuaces cuyos "inventores" o responsables frecuentemente carecen de hipocresía» (La voluntad de saber, pp. 115-116).

30 Así, por ejemplo, la fuerza «incita, induce, seduce, facilita o dificulta» (Foucault, M., «El sujeto y el poder», p. 253-4). Deleuze ha analizado con detalle esta cualidad de las fuerzas interpretando a Nietzsche, que es una de las fuentes esenciales de Foucault. Las fuerzas no pueden ser concebidas aisladamente y tampoco en función de una moral; más allá del bien y del mal, se afectan y son afectadas entre sí. Cfr. Deleuze, G., Nietzsche y la filosofía, Anagrama, Barcelona 1986 (orig.: 1962), pp. 14-20.

31 Foucault, M., «Polémica, política y problematizaciones», en Estética, ética y hermenéutica, p. 360. 
de fuerzas que operan, que acontecen, entrelazadas diferencialmente. Es «la proliferación de los acontecimientos», «muestra la heterogeneidad de lo que imaginábamos conforme a sí mismo» ${ }^{32}$. Por su parte, la «emergencia» designa «el punto de surgimiento. Es el principio y la ley singular de una aparición»" ${ }^{33}$. Contemplada la retícula de fuerzas desde este punto de vista, es un campo de surgimiento (Entstehungsherd) y el surgimiento se da en el intersticio de las fuerzas en dicho campo, o mejor, en el intersticio de los intersticios: se da en el nihil activo del «entre», "un "no-lugar", una pura distancia, el hecho de que los adversarios no pertenecen a un mismo espacio. Nadie es pues responsable de una emergencia, nadie puede vanagloriarse; ésta se produce siempre en el intersticio» ${ }^{34}$.

La dimensión de procedencia co-implicaría pues - y a nuestro juicio- a las positividades del saber en su nexo con las estrategias del poder, tomadas como pluralidad acontecimental, y mostraría la constitución del sujeto desde un campo diferencial. «Allí donde el alma pretende unificarse (...) el análisis de la procedencia permite disociar el Yo y hacer pulular, en los lugares y posiciones de su síntesis vacía, mil acontecimientos ahora perdidos» ${ }^{35}$. A su través, la dimensión del surgimiento co-implica al archivo y a la problematización en su nexo recíproco, como aspectos de un único acontecimiento, generado en el no-lugar del entre, y se revela como el responsable de una unidad del sujeto constituido, una unidad diferencial.

Alcanzado este punto del análisis se explicita la primera paradoja a la que aludíamos. La constitución del sujeto, que, por su propio sentido, posee un carácter coactivo, se funda, sin embargo, en una dimensión acontecimental, siendo así que el acontecimiento, también por su propio sentido, escapa a la mera coacción socio-política. Se funda en una dimensión que trasciende las facticidades institucionales y estratégicas. Además, el acontecimiento se nos ha revelado como «emergencia». ¿Qué presupone tal emergencia? A continuación intentamos mostrar que lo emergente invoca otra dimensión diferente a la «constitución»: la génesis.

2. CONSTITUCIÓN Y GÉNESIS. LAS DIMENSIONES DE LA «CONSTITUCIÓN» Y DE LA «GÉNESIS» EN LA «EMERGENCIA» DE LA SUBJETIVIDAD

Dejamos en suspenso, por el momento, este resultado, que atañe a la textura del sujeto como constituido e interrogamos por el sujeto como auto-constituyente. ¿En qué reside su «ser»? ¿Cómo podemos hablar de un sujeto que

32 Foucault, M., Nietzsche, la genealogía, la historia, Pre-Textos, Valencia 2004 (orig.: 1971), pp. 27 у 29.

33 Ibid., p. 33.

$34 \quad$ Ibíd., pp. 38-39.

35 Ibid., p. 26. 
se constituye a sí mismo en una relación auto-experiencial? En este punto, intentaremos mostrar que no podemos hablar, en rigor, en este otro ámbito, de un "sujeto», sino, por paradójico que se nos presente a primera vista, de un campo anónimo de auto-constitución, respecto al cual el sujeto «agente» es una expresión en superficie y al que, como veremos, es preciso conceptualizar, de un modo más preciso, como emergencia generadora. La cuestión planteada nos aparece a través de una aporía que pide, desde la obra misma de Foucault, una solución y que no ha encontrado en ella una formulación acabada. El pensamiento deleuzeano, como adelantamos, nos ofrece indicios para resolverla, y de un modo tal que, a nuestro juicio, se podría entender esa posible solución como contenida in nuce en los potenciales no desplegados de la distinción entre procedencia y emergencia a la que hemos llegado, por un camino que era completamente necesario recorrer en vistas a este momento álgido de nuestra pesquisa. Abordaremos primero el problema de la autoconstitución del sujeto -y, así, el de la génesis - en el ámbito de la ontología crítica de nosotros mismos. Con esa perspectiva más general, afrontaremos después la misma cuestión en el ámbito de la autoexperiencia en las prácticas de sí.

\subsection{Constitución y génesis en la ontología de nosotros mismos}

La dimensión de génesis de la subjetividad se encuentra inserta de diferentes modos en la filosofía deleuzeana. El objetivo de esta investigación no es el de profundizar en ella, sino el de aprovechar los aspectos relevantes que nos permitan ensayar si esta dimensión de la subjetividad es aplicable al planteamiento de Foucault como posible solución a las aporías en las que, a nuestro juicio, incurre la relación por él planteada entre sujeto constituido y auto-experiencia autónoma de la subjetividad. Nos centramos primero en el modo en que tal autoexperiencia tiene lugar en el ejercicio de la ontología de la actualidad u ontología de nosotros mismos, remontándonos, antes de nada, al hilo problemático en el que la noción de génesis se hará pertinente. Uno de los aspectos fundamentales de la filosofía deleuzeana se cifra, como en el caso de Foucault, en su conformación como una ontología del acontecimiento. Aunque el concepto de acontecimiento es, en ella, poliédrico, es destacable una de sus fundamentales acepciones, que introdujo ya en Lógica del sentido. El ser, que coincide con su propio acontecer, muestra su carácter diferencial en la relación entre el lenguaje y las cosas. El acontecimiento se nos desvela como diferenciante en una síntesis disyuntiva entre ambas, es decir, en un tipo de vínculo sintético que consiste en la relación misma entre lo vinculado, en el encuentro recíprocamente afectante entre series divergentes ${ }^{36}$, en este caso de proposiciones, por un lado, y de la materialidad de las cosas, los cuerpos, por otro. Expresado por la proposición y predicado como atributo de los cuerpos, no coincide con ninguna de estas

36 Cfr. Deleuze, G. Diferencia y repetición, Amorrortu, Buenos Aires 2002 (orig.: 1968), pp. 190 y ss.; Lógica del sentido, Paidós, Barcelona 1989 (orig.: 1969), octava serie, pp. 67-71. 
instancias. Investido en el verbo, ocupa el lugar del diferenciante en la relación entre ellas, lo que implica que su ser afecta a ambas sin identificarse con ellas: in-siste en la proposición y se realiza en las $\operatorname{cosas}^{37}$. Mediante una renovación de la ontología estoica, esto significa para Deleuze que el acontecimiento cobra realidad en los cuerpos, en sus enlaces o mezclas, como aquello que les ocurre sin confundirse con ellos. Es su extra-ser, una superficie metafísica consistente en el acontecer que les sobreviene y que, como el cortar del cuchillo en la carne, se efectúa en su materialidad.

El acontecimiento, así, no pertenece en exclusiva ni a lo puramente inteligible, ni a lo puramente material: es un telúrico incorporal ${ }^{38}$. Pero es precisamente en esta dirección en la que se propuso moverse expresamente Foucault, que se refería a su tratamiento, ya analizado, del orden del discurso y de los poderes a él vinculados como propio de una filosofía de lo incorporal-material:

El acontecimiento no es ni sustancia, ni accidente, ni calidad, ni proceso; el acontecimiento no pertenece al orden de los cuerpos. Y sin embargo no es inmaterial; es en el nivel de la materialidad como cobra siempre efecto, que es efecto; tiene su sitio, y consiste en la relación, la coexistencia, la dispersión, la intersección, la acumulación, la selección de elementos materiales; no es el acto ni la propiedad de un cuerpo; se produce como efecto de y en una dispersión material. Digamos que la filosofía del acontecimiento debería avanzar en la dirección paradójica, a primera vista, de un materialismo de lo incorporal ${ }^{39}$.

A pesar de este nexo entre los dos pensadores, habría que puntualizar que Foucault no adscribía el acontecimiento incorporal al dominio del lenguaje proposicional, sino, como vimos, a la pragmática discursiva, a la esfera de los enunciados, pues ésta es la que se ajusta a una comprensión del devenir como operari. Dejando a un lado qué dimensiones alcanzó el influjo de uno sobre otro, Deleuze confiesa mucho más tarde, en 1986, que no fue impasible en este aspecto. "El concepto que él formó de "enunciado" me produjo un gran impacto, porque implicaba una pragmática del lenguaje capaz de renovar la lingüística» ${ }^{40}$. Tras Lógica del sentido, y con el propósito de ampliar sus resultados al campo social, el acontecimiento es pensado desde esta dimensión. La enunciación es al mismo tiempo lingüística y práctico-social, es un devenir transformador de carácter operativo y colectivo, el agenciamiento. El modo de ser de éste es ese paradójico y diferencial al que nos hemos referido: el de una sintesis disyuntiva, el de un intersticio entre dos caras heterogéneas, una vuelta hacia el lenguaje (forma de expresión), otra hacia la materialidad social (forma de contenido). Este devenir autoalterante, el acontecimiento-agenciamiento, es pensado como una transformación incorporal que, por un lado, es expresada por el agenciamiento de enunciación y que, por otro, se efectúa en los estados de

37 Cfr. Deleuze, G., Lógica del sentido, pp. 35-46 y 188-191.

38 Cfr. Ibíd., pp. 25-35.

39 Foucault, M., El orden del discurso, p. 57.

40 Deleuze, G., «Hender las cosas, hender las palabras», en: Deleuze, G., Conversaciones. 1972-1990, Pre-Textos, Valencia 1999, p. 145. 
cuerpos, es decir, en la materialidad social, en sus articulaciones y sus modos de operar, en agenciamiento de efectuación ${ }^{41}$.

Este análisis deleuzeano del devenir enunciativo y del acontecimiento con él vinculado nos puede servir de prisma para interrogarnos con mayor profundidad acerca de la problemática que nos presenta el pensamiento de Foucault. Puede ayudarnos a reflexionar sobre la compleja y sutil relación entre la esfera del sujeto constituido y aquel otro campo al que habría que adjudicar un valor constituyente en cuanto supuesto de una experiencia de sí, de una vuelta auto-referencial capaz de hacer comprensible esa elaboración creativa de sí que tiene lugar a través de la ontología de nosotros mismos. Para alcanzar mayor claridad nos moveremos primero en el plano del saber, para preguntarnos, después, por la dimensión completa de los dispositivos saber-poder.

Manteniéndonos en el ámbito del saber, es preciso suponer, tal y como lo concibe Foucault, una intrincación —en terminología deleuzeana- entre forma de expresión y forma de contenido enunciativas en el sujeto, en la medida en que es constituido. En efecto, presenta dos caras heterogéneas: su ser-constituido en cuanto expresado en el devenir discursivo, en el decir, por un lado, y su ser-constituido en cuanto lo dicho en tal devenir, por otro. Es producido por esa dimensión ordenadora que expresa el propio discurrir enunciativo: el archivo; y es, al mismo tiempo, lo que tal acontecer realiza de manera efectiva: las positividades. La complejidad de la relación que encontrábamos entre ambos rostros del sujeto constituido proviene, como habíamos señalado, de la imposibilidad de distinguirlos a menos que se los comprenda el uno por el otro. Pues bien, sostener esta inter-penetración supone, al mismo tiempo y a nuestro juicio, que el acontecer, en cuanto tal, no es ni uno ni otro. Forman -empleando el concepto deleuzeano- una síntesis disyuntiva. Lo corrobora Foucault cuando formula el nexo entre el discurso y lo dicho en él como la heterogeneidad relacional o desfase entre el decir y el ver. Lo que es dicho en un enunciado no se agota en la relación intra-discursiva y, sin embargo, tampoco es una quimérica construcción; apunta, no a una «referencia» signable deícticamente, sino a un «referencial», el cual, más que una facticidad bruta o un estado de cosas objetivo, es un dominio en el que éstos pueden aparecer. Lo dicho, así, se mantiene heterogéneo al decir y desfasado de él como "una realidad visible» ${ }^{42}$, tal y como ocurre en la heterogeneidad entre el hospital, en cuanto visibilidad de la locura, y la medicina, como su decir ${ }^{43}$. Ahora bien, si esto es así, habría que dar por supuesto

41 Cfr. Deleuze, G. / Guattari, F., Mil mesetas, Pre-Textos, Valencia 2000 (orig.: 1980), pp. 81-90.

42 Foucault, M., La arqueología del saber, p. 150. Cfr., pp. 149-159.

43 Se trataría - nos ilustra Deleuze- de la relación de una no relación, tal y como ocurriría, en La historia de la locura, entre el hospital general —en cuanto forma de contenido o visibilidad de la locura - y la medicina - en cuyo discurso se da, en cuanto forma de expresión, la producción de enunciados de desvarío. La visibilidad de la locura, el hospital, tiene su origen, no en la medicina, sino en la policía. Por su parte, la medicina despliega su discurso, sus tratamientos y métodos, fuera del hospital. Cfr. Deleuze, M., Foucault, pp. 90-91. 
que, en realidad, en el pensamiento foucaultiano lo que ha de ser comprendido como acontecimiento, lo que acontece, no es exactamente el ser-constituido del sujeto (a través del saber-poder), como si tal proceso fuese el centro del devenir. El acontecimiento sería, más bien, el diferenciante del proceso disyuntivo de tal ser-constituido como devenir, el diferenciante entre las formas de visibilidad y las del decir. El acontecimiento es ambos y ninguno en particular, los relaciona o los pliega. Esta interpretación a la que nos vemos conducidos es la que, precisamente desarrolla Deleuze en sus textos sobre Foucault ${ }^{44}$. El acontecimiento une y separa - de otro modo- las dos caras heterogéneas de la constitución del sujeto: la cara material, especificada en la multiplicidad de las positividades (y perteneciente al dominio del ver) y la inmaterial que las reúne en sus diferencias sin anularlas, el archivo, inserto en el decir o acto de enunciar. ¿Y qué instancia es la de este acontecimiento expresado en el archivo lingüístico y efectuado positivamente en los cuerpos? Tal acontecimiento es —en el caso de Deleuze y coherentemente con lo que se viene señalando- el que permite dar testimonio de la existencia de ambos y aprehenderlos en su relación diferencial: el pensamiento. Se trata de un pensar a-subjetivo, tal y como aparecía en Lógica del sentido, que discurre entre las proposiciones y las cosas, pero ahora no hace emerger el sentido, no es un acontecimiento-sentido; es operativo, se pone en obra en la experimentación ${ }^{45}$. Sin eliminar la distancia entre las filosofías deleuzeana y foucaultiana, ¿no se podría decir que hemos de suponer una instancia semejante a este "acontecimiento-pensamiento» como condición de la auto-experiencia creadora en el caso de Foucault? ¿No sería condición de la forja de sí que se pone en obra en la foucaultiana ontología crítica de nosotros mismos?

Desde el punto de vista foucaultiano, una ontología de nosotros mismos lleva en sí, como práctica y no sólo como concepción teórica, una auto-experiencia pensante. Quiere decir esto que no consiste ni en una pura teoría ni en una mera práctica aplicativa. Es Aufklärung, un esclarecimiento crítico, directamente teórico-práctico, una "práctica histórico-filosófica» que integra una investigación filosófica de la historia y un "hacerse su propia historia» ${ }^{46}$. La Ilustración, considerada en su ethos, debe ser, ante todo, una actitud, pero no reductible de modo psicologista, pues aúna el análisis de cómo hemos sido conformados y la confrontación transformadora de tal conformación mediante el uso público de la razón al que se refería Kant, reconduciendo el análisis de sus condiciones puras, necesarias y universales, a la cuestión acerca de cómo «puede el uso de

44 Cfr. Deleuze, G., Foucault, pp. 75-98 y Deleuze, G., El saber. Curso sobre Foucault, Cactus, Buenos Aires 2013 (orig.: 1985), especialmente pp. 119-159.

45 «Un agenciamiento, en ese sentido, es una verdadera invención» (Deleuze, G. / GuatTaRI, F., Mil Mesetas, p. 408). Esta es precisamente la base de la experimentación: ningún sentido a descubrir detrás de los signos. «Experimenta en lugar de significar y de interpretar» (Ibid., p. 141).

46 Cfr. Foucault, M., "¿Qué es la crítica?»" (orig.: 1978), en: Sobre la Ilustración, Tecnos, Madrid 2003, pp. 3-52, pp. 19-21. 
la razón tomar la forma pública que le es necesaria, cómo la audacia de saber puede ejercerse a la luz del día ${ }^{47}$. Es una actitud de modernidad, comprendiendo por «actitud» «una relación con respecto a la actualidad (...), una manera de pensar y de sentir, una manera también de actuar y de conducirse» ${ }^{48}$. La ontología de nosotros mismos, por tanto y a nuestro juicio, es un pensamiento operante que indaga y actúa al unísono. Es, diríamos, acontecimiento-pensamiento, si se cifra el carácter del pensar en lo que describiríamos como un lúcido agere problematizador. Busca, en lo que nos hace ser lo que somos, las problematizaciones emergentes y las confronta in actu, problematizando desde ellas la existencia, de manera que ésta logre una alteración autoinventiva y autocreadora, como si fuera, tal como quería Baudelaire, una obra de arte a modelar. Esta práctica histórico-filosófica en la que consiste la ontología de nosotros mismos es, así, pensamiento en obra, por medio del cual la filosofía se hace inseparable de su ejercicio: no una teoría, una doctrina, ni siquiera un cuerpo permanente de saber que se acumula, sino «una vida filosófica»" ${ }^{49}$. Pues bien, este acontecimiento-pensamiento que habría que propiciar es capaz de innovar precisamente por esta cualidad problemática que la transita; es experimental ${ }^{50}$.

La experimentación, precisamente, es el carácter intrínseco, para Deleuze, del agenciamiento-pensamiento, en la medida en que da lugar a la organización de culturas e incluso edades al «introducir las discontinuidades selectivas en la continuidad», operando así como «una verdadera invención» ${ }^{51}$. ¿Cómo es generado en él —nos interrogamos ahora- lo nuevo? El dinamismo del acontecimiento-agenciamiento implica un devenir en el que se producen, como hemos dicho, transformaciones incorporales. Hay momentos de tal devenir en el que tales transformaciones alcanzan gran intensidad y complejidad. Se trata de mutaciones posibles en espacios de crisis, a propósito de acontecimientos como el de mayo del 68. Las circunstancias abruman entonces y se experimenta colectivamente un ocaso y la necesidad de lo posible. El acontecimiento, en este ejemplo, que incita a una trasformación incorporal, se lee en la angustia in actu: "Lo posible, que me ahogo». Ahora bien, este incorporal se realiza inmediatamente como agenciamiento de efectuación y, de ese modo, corre la suerte de su muerte, de su disolución en hechos concretos. De esa muerte lo rescata el colectivo sólo si ejerce una contraefectuación, es decir, si arranca al acontecimiento de esa disolución efectuante y lo retrotrae a su condición de acontecimiento puro, ahí donde ya no tiene una temporalidad en Chronos, sino una densidad en la eternidad del instante, Aión. Es entonces cuando el acontecimiento se yergue como quicio entre lo intolerable y la posibilidad en cuanto

47 Foucault, M., «¿Qué es Ilustración?» (orig.: 1983), en: Sobre la Ilustración, pp. 71-97, p. 78 .

48 Ibíd., p. 81.

49 Ibíd., p. 97. Cfr. pp. 86-97.

50 Ibid., p. 92.

51 Deleuze, G. / Guattari, F., Mil mesetas, p. 408; opera como máquina de guerra. Cfr. pp. 405-415. 
tal, apelando a una nueva subjetividad, es decir, a una mutación social ${ }^{52}$. La apelación, en ese trance, proviene de la virtualidad del acontecimiento, que, transfigurado en una reserva pura, en una espera infinita, obliga a una colectividad a estar a la altura de merecerlo, creándose de un modo-otro ${ }^{53}$.

Cabe concluir que La subjetividad, es decir, el sujeto en cuanto auto-experiencial y auto-constituyente, no es el acontecimiento mismo, pero sí una subespecie del acontecimiento: es la forma de expresión que anticipa formas de contenido en ciernes, en tanto que interviene en ellas realizando transformaciones incorporales o de sentido que se atribuyen a los cuerpos ${ }^{54}$. La problemática relación, a la que volvemos, entre el sujeto constituido e instancia auto-constituyente en el pensamiento foucaultiano, se intensifica. La subjetividad auto-experiencial y supuestamente auto-constituyente no sería, ella misma, un inicio, sino una consecuencia; es producida por el acontecimiento-agenciamiento. Éste es el que realmente merecería la calificación de instancia constituyente. Y, en efecto, Foucault no apela, con el emblema «ontología de nosotros mismos» a una subjetividad que actuaría de fondo y que se revelaría o desvelaría. La subjetividad ahí invocada es, paradójicamente, un efecto del acontecimiento que se espera de ese ethos que nos sitúa en la actualidad. Pues actualidad es actitud límite, más allá del mero rechazo de aquello que nos constituye para extraditarnos a un exterior. «Se debe escapar de la alternativa del afuera y del adentro; es preciso estar en las fronteras ${ }^{55}$. Tal subjetividad del intersticio no es, dicho con Deleuze, un adentro al que se apela y que pre-existe al afuera que discurre, sino un pliegue del afuera ${ }^{56}$. Esta tesis deleuzeana necesita, no obstante, aclaraciones previas relativas a la noción de génesis

El problema al que hemos llegado reside en la siguiente cuestión. ¿Cómo aparece una subjetividad, una vuelta autoexperiencial, que debe ser considerada

52 Dado que en Francia, nos dice Deleuze, una contraefectuación así fracasó, se puede decir con rigor que «Mayo del 68 no ocurrió». Cfr. Deleuze, G., «Mayo del 68 no ocurrió» (orig.: 1984), en: Dos regímenes de locos, op. cit., pp. 213-215. Para el ejemplo análogo, pero exitoso, del acontecimiento, genialidad de la $1^{a}$ Internacional, en la que ésta inventa una nueva clase social a través del acontecimiento contra-efectuado "iProletarios de todos los países, uníos!», V. Deleuze, G. / Guattari, Mil Mesetas, pp. 88 y ss. V. también Deleuze, G. / Guattari, F., ¿Qué es filosofía?, Anagrama, Barcelona 1993 (orig.: 1991), pp. 157-163.

53 La fuerza para la contraefectuación pertenece a la filosofía, por lo demás, como forma de vida. "Hay una dignidad del acontecimiento que siempre ha sido inseparable de la filosofía como "amor fati": igualarse con el acontecimiento, o volverse hijo de los propios acontecimientos (...). La filosofía no tiene más objetivo que volverse digna del acontecimiento, y quien contra-efectúa el acontecimiento es precisamente el personaje conceptual»(Deleuze, G. I GUATTARI, ¿Qué es filosofía?, p. 161).

54 Así lo glosa, en su magnífico trabajo, Alcalá Rodríguez, F. J. «Of the Processes of Subjectivation as a Subspecies of the Event: the Deleuzian Reading of the Later Foucault», en: CLC Web: Comparative Literature and Culture, vol. 20.4 (2018), article 10, p. 7.

55 Foucault, M., «¿Qué es Ilustración?», pp. 90-91.

56 Deleuze aclara así, como veremos, a la subjetividad que moviliza al cuidado de sí, pero, a nuestro juicio, es aplicable igualmente en este contexto. Cfr. Deleuze, G., La subjetivación. Curso sobre Foucault, Cactus, Buenos Aires 2015 (orig.: 1986), pp. 5-38. 
agente de una auto-alteración, por un lado, e instancia producida, por otro, en el acontecimiento de tal alteración? Foucault, a nuestro juicio, no responde a esta cuestión, sino que simplemente la plantea. Parte, en la línea de lo que venimos analizando, del supuesto de una historia sin sujeto, pero que comporta, en el quicio del franqueamiento de las condiciones que nos constituyen, "un trabajo nuestro sobre nosotros mismos en tanto que seres libres ${ }^{57}$. Hay, pues, que suponer una instancia que es, a la vez, a-subjetiva y suelo de subjetividad. Esta instancia, que es la dimensión auto-constituyente por la que interrogamos, podría ser aclarada recurriendo a la noción de génesis que Deleuze emplea y que tiene raíces en G. Simondon. Foucault había rechazado este término al vincular la ontología de nosotros mismos a la genealogía, entendiendo por "génesis» el recurso "hacia la unidad de una causa principal cargada de una descendencia múltiple ${ }^{58}$. Y, si bien este es uno de sus sentidos, es precisamente a su sentido opuesto a lo que nos referimos. La génesis, en el espacio de pensamiento simondoniano-deleuzeano, se refiere a la gestación de la unidad del «sujeto» desde una pluralidad de relaciones diferenciales y problemáticas de fondo. Está ligada al principio de individuación, por el cual se intenta explicar cómo llega a ser la individualidad de un ente a partir de la indiferenciación de la naturaleza o del universo como un todo indiviso. En nuestro contexto, se trata de la individuación de la subjetividad humana desde el fondo indiferenciado de la naturaleza considerada como physis. Que la subjetividad sea, desde este ángulo de análisis, una "producción» no significa que sea incapaz de ejercer la espontaneidad activa en el movimiento auto-experiencial. Significa que tal espontaneidad activa se funda en la potencia, en sí misma a-subjetiva, de lo natural.

Habría que entender, en primer lugar, al acontecimiento, a este precursor que es el único agente al que nos retrotrae el pensamiento foucaultiano, como lo virtual que se efectúa en lo actual, siendo la génesis el paso del primero al segundo. El acontecimiento, en cuanto virtual, no se opone a lo real, nos dice Deleuze. Posee una realidad plena. Es el modo de ser de lo acontecimental, pues éste in-siste como una red de diferencias intensivas (de las cuales es el diferenciante) que se actualizan en el plano de la extensión. Lo virtual-diferencial posee un carácter problemático: es un verdadero conjunto de problemas, en cuanto relaciones tensionales, en cuanto heterogeneidades vinculadas por el encuentro disyuntivo. Su actualización es también, desde este último punto de vista, su solución, entendida ésta como corporeización o efectuación material $^{59}$. En este sentido, explicita de otro modo la relación entre lo que llamamos dimensión vertical del acontecimiento en Foucault y la correspondiente dimensión horizontal. Podríamos decir, desde esta perspectiva, y en primer lugar, que el archivo es lo virtual respecto a su actualización en las positividades. El propio

57 Ibid., p. 93.

58 Foucault, M., «¿Qué es Ilustración?», p. 31.

59 Esta noción recorre toda la obra deleuzeana. Cfr., por ejemplo, Deleuze, G., Diferencia y repetición, pp. 315-320. 
Foucault incita esta interpretación. El archivo, que es la dimensión ordenadora de las positividades que nos constituyen, no está jamás ante nosotros, sino que es nuestro subsuelo. «En su totalidad — nos dice Foucault- el archivo no es descriptible, y es incontorneable en su actualidad (...), es lo que, fuera de nosotros, nos delimita (...), nos desune de nuestras continuidades: disipa esa identidad temporal en que nos gusta contemplarnos a nosotros mismos (...). Establece que somos diferencia ${ }^{60}$. Es, podríamos decir, un campo diferencialvirtual que se actualiza en las positividades discursivas que nos constituyen, y esta interpretación viene sugerida, incluso, por el modo en que Foucault se refiere a la relación entre archivo y positividades: «La actualización jamás acabada, jamás íntegramente adquirida del archivo, forma el horizonte general al cual pertenecen la descripción de las formaciones discursivas, el análisis de las positividades, la fijación del campo enunciativo" ${ }^{61}$. Ahora bien, el saber no se basta a sí mismo. Es necesario remitirlo al poder, con el que está intrincado. En este sentido, en segundo lugar, se puede comprender el campo de las fuerzas en relación -y, por tanto, la problematicidad que comporta- como dimensión virtual que se actualiza en las estrategias de facto. Es a este virtual al que Deleuze otorga el rango prioritario del afuera. Foucault ya se había referido a la inmanencia en estos términos. Si partiésemos del sujeto como un ámbito de identidad y de intimidad, el afuera es un fuera de sí respecto al cual el primero es su interioridad ${ }^{62}$. Deleuze ha concretado el afuera como el espacio de las relaciones diferenciales entre fuerzas. Explicar cualquier instancia representable, unitaria y ordenada conforme a una apariencia de identidad equivale, en la geofilosofía deleuzeana, a hablar de pliegue del afuera. No es nuestro propósito circunscribir el vasto conjunto de fenómenos que la conceptualidad del pliegue implica. Baste señalar, en el hilo de nuestra indagación, que la relación entre lo virtual y lo actual, contemplada desde esta perspectiva, es la de un pliegue. El pliegue, en general, es el tipo de relación entre el ámbito informal de las fuerzas y el formalizado por éstas. Aunque, como vimos, Foucault ha ligado desde el comienzo de su investigación el saber al poder, para Deleuze el paso de la etapa arqueológica foucaultiana a la genealógica expresa la necesidad de explicitar tal relación. El saber - por decirlo así- nos con-forma, otorga una forma con apariencia de identidad al sujeto constituido, pero en él no reside la capacidad generativa. «El poder es justamente ese elemento informal que atraviesa las formas del saber, que está bajo ellas. Por eso se llama microfísico. Es fuerza, relación de fuerzas, no forma ${ }^{63}$. El archivo - a nuestro juicio y en la línea de Deleuze- es, como hemos dicho, acontecimiento, pero porque está involucrado en el dinamismo de la formalización de las fuerzas (o actualización). Es acontecimental derivadamente, en la medida en que es contemplado como

60 Foucault, M., La arqueología del saber, pp. 221-223.

61 Ibid., p. 223.

62 Foucault, M., El pensamiento del afuera, Pre-Textos, Valencia, 2000 (orig.: 1986), p. 18. Cfr. pp. 15-22.

63 Deleuze, G., Conversaciones, p. 159. 
potencia ordenadora. Esta potencia ordenadora acompaña siempre al saber, al archivo, pero concierne a las fuerzas que lo atraviesan. Entre lo virtual y lo actual no hay una relación de precedencia-consecuencia extensivas, sino una coimplicación, equivalente a la que guarda la cualidad intensiva con su encarnación extensa. Lo actual es el pliegue de lo virtual: lo actual es el «adentro» que resulta del pliegue de este afuera informal poblado de fuerzas. Pues bien, la diferencia entre esta dimensión virtual-intensivo-diferencial de las fuerzas, por un lado, y su actualización o plegado en lo representativo-efectual-extenso de lo macrológico, por otro, estaría ya en lo impensado de Foucault o en lo por él supuesto cuando concebía el campo del poder, en su profundidad, como «microfísica» ${ }^{64}$. Ahora bien, lo microfísico, ¿no sería lo informal generativo respecto a lo formal-generado? ¿No cabría distinguir esta última relación —en cuanto dinamismo vertical atribuible a la génesis - de la relación - horizontal- entre la constitución y lo constituido, asignable al mundo socio-cultural? A nuestro juicio sí, si no separamos lo social y la naturaleza como si fuesen esferas inconmensurables y, por el contrario, partimos del supuesto de su recíproca inter-dependencia.

El pensamiento foucaultiano parece encerrarse en los límites del mundo social, excluyendo el lazo de éste con el sustrato de la naturaleza. Ambos, mundo socio-cultural y político, por un lado, y mundo natural, por otro, están entrelazados, son inseparables, aunque han de ser considerados, al mismo tiempo, como diferentes. Se presuponen en su disyunción. La "constitución del sujeto" sería, entonces, un fenómeno asignable a la vida socio-cultural y política, mientras que la "génesis» convendría a la emergencia de la subjetivad en el seno de la naturaleza tomada como physis. A nuestro juicio, esta conclusión puede ser apoyada en el pensamiento deleuzeano. En éste se tematiza un plano vertical de la naturaleza, cuyo fondo es el campo informal trabado por la relación intensiva de las fuerzas, al que ha llamado Deleuze en ciertas ocasiones cuerpo sin órganos de la tierra ${ }^{65}$. Tal profundidad intensiva e informal se cruza, en el proceso de génesis, con el plano horizontal en el que tiene lugar su articulación formal. Este último no coincide tout court con las configuraciones sociales, sino que posee distintos niveles, desde los códigos químicos, genéticos, celulares, etc., hasta las conformaciones socio-políticas. Habla, así, Deleuze, de una doble articulación: la primera articulación - que corresponde a lo molecular«seleccionaría o extraería, de los flujos-partículas inestables, unidades moleculares o cuasi moleculares metaestables (...)»; la segunda —correspondiente

64 «No se trata de una especie de distribución democrática o anárquica del poder a través de los cuerpos (...). Más bien se debe hacer un análisis ascendente del poder, arrancar de los mecanismos infinitesimales, que tienen su propia historia, su propio trayecto, su propia técnica y táctica y ver después cómo estos mecanismos de poder han sido y todavía están investidos, colonizados, utilizados, doblegados, transformados, desplazados, extendidos, etc. por mecanismos más generales y por formas de dominación global» (Curso del 14 de enero de 1976, en: Microfísica del poder, pp. 144-145).

65 Deleuze, G., Mil mesetas, pp. 47-48. 
a lo molar - «sería la encargada de crear estructuras estables, compactas y funcionales ${ }^{6}{ }^{6}$. La naturaleza, entretejida finalmente con lo socio-político, adquiere así el carácter de una physis auto-generadora o auto-poiética: «el arte no espera al hombre para comenzar ${ }^{67}$, «ya no se sabe lo que es arte o lo que es naturaleza» ${ }^{68}$.

Estas consideraciones permitirían, en definitiva, diferenciar los procesos sociopolíticos de constitución del sujeto y la génesis de la subjetividad. La subjetividad auto-experiencial involucrada en la ontología de nosotros mismos sería un efecto, como pretende la filosofía foucaultiana, pero - a nuestro juicio- no respecto al saber y a las estrategias del poder a ella vinculadas; es efecto del fondo anónimo de las fuerzas a través de un proceso de génesis. En un plano horizontal, la subjetividad es constituida; en un plano vertical, es generada. Tal subjetividad, en el ámbito filosófico deleuzeano, puede ser analizada desde dos puntos de vista fundamentales. Desde el punto de vista, en primer lugar, de la génesis individuadora de la subjetividad de lo humano en cuanto tal. Desde ella se comprende tal subjetividad como la espontaneidad activa de lo humano en general, en cuanto arraigada en una pasividad pre-subjetiva: es una tentativa, siempre titubeante, de integración de la pluralidad informal de un pensamiento-problema en profundidad. Pensamiento-problema en la medida en que es una articulación diferencial o relacional problematizante, condición de posibilidad genética de una problematización expresa ${ }^{69}$. Desde otra terminología, se trata del agenciamiento-pensamiento en cuanto acontecimiento virtual que se actualiza en la efectividad de la subjetividad humana o, finalmente, de un pliegue de tal ámbito virtual entendido como afuera de las fuerzas en relación, un pliegue de este afuera cuyo adentro es la subjetividad humana. El «nosotros» foucaultiano de la ontología de nosotros mismos sería, en su profundidad - y en sintonía con estas conclusiones- lo Actual en cuanto virtual que se efectúa en la actualidad concreta de lo que somos: este intersticio entre lo que estamos dejando de ser y lo que comenzamos a ser. Expresado con Deleuze, lo Actual no es ni pasado ni futuro. Como un análogo de lo Intempestivo en Nietzsche o de lo Internal en Péguy- es el devenir puro y acontecimental que genera nuestro «devenir-otro» en su efectuación ${ }^{70}$. En segundo lugar, y desde el punto de vista de la particularidad del sí mismo individual, se trata de la génesis individuadora como haecceidad desde un campo impersonal ${ }^{71}$. Excede los límites de este trabajo abordar estas temáticas en detalle. En cualquier caso, habría que

${ }^{66}$ Ibíd. Cfr. pp. 47-52.

67 Ibid., p. 326.

68 Deleuze, G. / Guattari, F., ¿Qué es filosofía?, p. 187. Cfr. para esta temática Galván Rodríguez, G., G. Deleuze. Ontología, pensamiento, lenguaje, Ed. Universidad de Granada, Granada 2007, cap. 6.3.

69 Cfr. Deleuze, G., Diferencia y repetición, pp. 141-176.

70 Cfr. Deleuze, G. / Guattari, F., ¿Qué es filosofía?, p. 114.

71 Cfr. Deleuze, G. / Guattari, F., Mil mesetas, pp. 264 y ss. 
concluir que entre la génesis de la subjetividad de este «nosotros» de la ontología de la actualidad y la constitución sociopolitica del sujeto hay una intrincación.

\subsection{Constitución y génesis en las prácticas de sí}

Terminamos nuestra reflexión sintetizando la problematicidad del sí mismo supuesto en Foucault al abordar las prácticas del cuidado de sí, un sí mismo en el que rastreamos la segunda perspectiva deleuzeana mencionada relacionada con el principio de individuación.

El problema que nos concierne, la aporética relación entre sujeto constituido y auto-experiencia de la subjetividad, se concreta, a nuestro juicio, dentro del ámbito de los estudios foucaultianos sobre las prácticas de sí, en el modo en que concibe la verdad en dicha esfera. Son tres las tematizaciones de Foucault en esta dirección. En primer lugar, la verdad está ligada al autoconocimiento, que entra en colisión con el cuidado de sí, sobre todo en el curso de 1982 sobre la hermenéutica del sujeto. Se refiere Foucault a la epimeleia heautou, o a la latina cura sui, como "el principio de que uno debe "ocuparse de sí", "preocuparse por sí mismo" ${ }^{72}$. Tal principio tuvo una relación tensa con el del conocerse a sí mismo, el gnothi seauton. En las prácticas del cuidado de sí siempre hay logoi, «discursos verdaderos», pero no porque explicitasen la verdad del sujeto, sino porque sirven al fin de conseguir el autodominio resistiendo a los acontecimientos que puedan doblegarnos y esclavizarnos. Estos logoi, o en latín, veridica dicta, permiten conjurar nuestros temores evitando ese vasallaje respecto a lo que nos ocurre. «En consecuencia, tenemos todo un conjunto de técnicas cuya meta es ligar la verdad y el sujeto. Pero hay que comprenderlo con claridad: no se trata de descubrir una verdad en el sujeto (...). Se trata, por el contrario, de proveer al sujeto de una verdad que no conocía y que no residía en él; se trata de hacer de esta verdad aprendida, memorizada, progresivamente puesta en aplicación, un cuasi sujeto que reina soberanamente en nosotros ${ }^{73}$.

La verdad hace relación, en segundo lugar, a la parrhesía, el coraje de la verdad, en el contexto de la gubernamentalidad, ante todo en el curso de 1983 sobre el gobierno de sí y de los otros. Se trata de la palabra destinada a un hablar franco en la democracia, tan necesario en ésta como la isegoría (igualdad en las posibilidades de uso de la palabra $)^{74}$. Lo esencial en este ámbito es la pregunta acerca de quién puede gobernar a los otros. La respuesta es que puede hacerlo quien se gobierna a sí mismo. La verdad no estaría destinada, según ello y de nuevo, a la caracterización de una naturaleza del sujeto, sino a prevalecer, mediante el coraje y mostrando el propio autogobierno, en una lucha agonística en las condiciones de ciudadanos libres. En tal sentido, ni siquiera se orienta a revelar una supuesta cualidad intrínsecamente superior: «la parrhesía es algo

72 Foucault, M., La hermenéutica del sujeto, p. 455.

73 Ibíd., p. 463. Cfr. pp. 460-463.

74 Cfr. Foucault, M., El gobierno de sí y de los otros. Curso del Collège de France. 19821983, Akal, Madrid 2011, pp. 133-151. 
que va a caracterizar mucho menos un estatus, una posición estática, un rasgo clasificatorio (...) que una dinámica (...), pone al individuo en una posición de superioridad gracias a la cual podrá ocuparse de la ciudad bajo la forma y por el ejercicio del decir veraz» ${ }^{75}$.

La verdad, en tercer lugar - y este sentido nos parece el más sutil—, se relaciona con una parrhesía que irrumpe críticamente en la sociedad mostrando lo que significa una verdadera vida (alethés bios), sobre todo en el curso de 1983-1984 sobre el coraje de la verdad. Ésta se pone en obra, especialmente, en los cínicos, en los que tendría una función aletúrgica. Ahora bien, la verdad no remite a la esencia de la vida. Sirve operativamente para mostrar la otreidad de la propia vida. «En la vida cínica no hay intimidad, no hay secreto, no hay inexistencia de publicidad. (...) Visibilidad absoluta de la vida cínica. Pero esa dramatización, esa teatralización del principio de no disimulación, se acompaña enseguida de una inversión de sus efectos, de modo que la vida cínica, que es en realidad la más fiel a aquel principio, aparece, por el hecho mismo de esa radicalización, como radicalmente otra e irreductible a todas las demás» ${ }^{76}$.

En los tres casos, la problematicidad del planteamiento foucaultiano consiste - como en la ontología de nosotros mismos - en pensar una subjetividad como autoexperiencia que ha de ser auto-constitutiva, por un lado, y que no tiene, sin embargo y por otro, ninguna realidad fuera del poder. De otro modo: la subjetividad muestra en las prácticas de sí una verdad del poder, es decir, una verdad que está al servicio del poder sobre sí (potestas sui); pero no hay, de ningún modo, un poder de la verdad, es decir, ninguna potencia vinculada a la verdad misma inherente a la subjetividad. Y si esto es así, si no hay un más allá del poder, y el poder hace del sujeto, mediante dispositivos, un producto, si lo convierte en constituido, ¿cómo se explica la libertad del sujeto, su capacidad para constituirse a sí mismo?

Es ciertamente convincente que la resistencia del sujeto a su constitución - como argumenta Foucault — está supuesta en la articulación misma del poder, si lo entendemos, no como «dominio», sino como relaciones de fuerzas que comportan una afección recíproca. En ese sentido, las relaciones de influjo en las que se quiere cambiar la conducta del otro, son, en cuanto afecciones recíprocas, asimétricas, pero móviles y reversibles, lo cual permite presuponer, como su condición — dice Foucault en 1984-, procesos de libertad y resistencia, cosa que no ocurriría en la situación extrema del «dominio», en el que tales relaciones estarían «fijadas a perpetuidad ${ }^{77}$. Ahora bien, al argumentar de este modo, Foucault está remitiendo el poder, no al marco socio-político de influjos y resistencias exclusivamente, sino a un afuera más lejano. Este problema preocupaba a Deleuze. «Foucault se aferraba todavía al segundo eje [el poder], diciendo que esos puntos de resistencia son la simple contracara de las relaciones

$75 \quad$ Ibid., p. 140.

76 Foucault, M., El coraje de la verdad. El gobierno de sí y de los otros, II. Curso del Collège de France, 1983-1984, Akal, Madrid 2014, p. 232. Cfr. pp. 229-243.

77 Foucault, M., «Ética del cuidado de sí como práctica de la libertad», p. 405. 
de fuerzas (...) ¿Cómo podía decir que eran simples contracaras, cuando la contracara de la fuerza afectante es la fuerza afectada, no la resistencia? (...) ¿no dan testimonio los puntos de resistencia de un afuera directo, de un afuera inmediato? $\gg^{78}$. Habría que pensar, como para el caso de la ontología de nosotros mismos, en un afuera en el que la subjetividad auto-experiencial, por así decirlo y a nuestro juicio, tocase roca dura.

Deleuze tiene un modo muy sutil de plantear esta cuestión, que nos permite precisar la idea de una génesis de la subjetividad. Como hemos visto, la subjetividad sería el pliegue del afuera. Y se plantea ahora dicho afuera en toda su radicalidad, es decir, como un «afuera absoluto». Dicho afuera absoluto coincidiría para el ser humano, para la subjetividad, en la muerte. Sería lo que Blanchot llama "lo imposible», la muerte personal. Y, sin embargo, pareciera que el compromiso con la realidad condujese a ese límite donde ya no hay ningún adentro. "Quien se consagra a la obra es atraído hacia el punto en que ésta se somete a la prueba de la imposibilidad. Experiencia específicamente nocturna, experiencia de la noche ${ }^{79}$. Ese afuera es, respecto a la subjetividad, el «se», el afuera más lejano - y más próximo, sin embargo-, la frontera irrebasable, la línea del afuera, cuyo espanto, nos dice Deleuze, es lo que impulsa al sujeto a plegar el afuera y hacerse a sí mismo, encontrar una interioridad. "Yo digo que hace falta a cualquier precio que la línea del afuera haga un pliegue, pues de lo contrario es invivible (...) Y es en ese pliegue donde podemos vivir, respirar y movernos ${ }^{80}$. A ese anónimo último se había referido Foucault como el hundimiento y desaparición de la subjetividad. «Este pensamiento que se mantiene fuera de toda subjetividad para hacer surgir como del exterior sus límites, enunciar su fin ${ }^{81}$. Pues bien, ese afuera no puede ser limitado, a nuestro juicio, a la esfera social. Es la naturaleza, campo de fuerzas, desde cuyo fondo se opera, según Simondon, no sólo la individuación, sino también la individualización, la génesis de la subjetividad individual, personal ${ }^{82}$. El propio Foucault había ilustrado con la noción de «emergencia» —como objetivo de análisis de la genealogía junto al de la "procedencia»— «la emergencia de una especie (animal o humana)» ${ }^{83}$, pero permaneció en el exclusivo campo socio-político. De nuevo, como en el caso de la ontología de nosotros mismos, la subjetividad de la que habla Foucault resulta insosteniblemente aporética si no la ligamos a una génesis desde la naturaleza. A ella, como hemos señalado, ha sido dedicado el análisis de la haecceidad, génesis de la individualidad desde el «se» profundo

78 Deleuze, G., La subjetivación. Curso sobre Foucault, p. 12.

79 Blanchot, M., El espacio literario, Paidós, Barcelona 1992 (orig.: 1955), p. 153. Cfr. cap. 5.1 .

80 Deleuze, G. La subjetividad, p. 28.

81 Foucault, M., El pensamiento del afuera, p. 16.

82 Cfr. Simondon, G., La individuación a la luz de las nociones de forma y de información, Cactus, Buenos Aires 2005 (orig.: 1958), pp. 395-405.

83 Foucault, M., Nietzsche, la genealogía, la historia, p. 34. 
e informal de las fuerzas. Pero este asunto rebasa los límites de la presente investigación.

La subjetividad supuesta, tanto en la ontología de nosotros mismos como en las prácticas del cuidado de sí, presupone - tal es nuestra conclusión- una intrincación entre su constitución desde dispositivos saber-poder en el ámbito socio-político, por una parte, y su génesis, por otra, desde la dimensión plástica e informal de la naturaleza como physis. Entre ellas no hay una polaridad rígida, pues la génesis desde lo informal se produce conformando formalizaciones a distintos niveles (físico, biológico, cultural y sociopolítico). La relación entre constitución y génesis de la subjetividad implicaría, para su análisis pormenorizado, un estudio de la compleja relación, disyuntiva en su unidad, entre cultura y naturaleza ${ }^{84}$.

Facultad de Filosofía y Letras de la Universidad de Granada

Luis SÁEZ RuEda

Departamento de Filosofía II

Campus Universitario de Cartuja, 18071 Granada

lsaez@ugr.es

https://www.ugr.es/ lsaez/

[Artículo aprobado para publicación en febrero de 2020]

84 Hemos intentado abordar esta cuestión en SÁEz RuEdA, L., El ocaso de Occidente, Herder, Barcelona 2015, parte primera. 